\title{
19. TETRAPYRROLE PIGMENTS IN DSDP LEG 38 SEDIMENTS
}

\author{
Earl W. Baker, Susan E. Palmer, and Katherine L. Parrish, Department of Chemistry, \\ Northeast Louisiana University, Monroe, Louisiana
}

\section{INTRODUCTION}

Thirty-four cores from eight sites drilled in the Norwegian-Greenland Sea were examined for tetrapyrrole pigment content. (See Table 1 for sample description.)

The major thrust of this investigation was to discover the distribution of tetrapyrrole pigments with respect to geologic age and depth of burial. The bulk of the conclusions drawn here is based on the UV-visible absorption data obtained from the core extracts.

\section{SAMPLES AND PROCEDURES}

All cores were stored frozen until the time of analysis. Where sample size permitted, $100 \mathrm{~g}$ (wet weight) were used for each analysis. Since only small core wedges were provided from Sites 341 and $344,50 \mathrm{~g}$ (wet weight) of sample were examined.

The procedures followed for the extraction and isolation of tetrapyrrole pigments from these cores have been described in previous Initial Reports (Baker and Smith, 1973; Smith and Baker, 1974; Baker and Smith, 1975a). An experimental flow sheet is presented in Figure 1.

A Beckman ACTA CIII ultraviolet-visible scanning spectrophotometer was used to obtain absorption spectra. Mass-spectral data were obtained using a DuPont 21-491-BR mass spectrometer equipped with a solid sample probe inlet system and digital mass marker. The pigment sample was applied to the rounded end of a 2 $\times 15 \mathrm{~mm}$ sealed-glass capillary tube inserted into the probe rounded end out. This method of sample introduction brings the sample closer to the electron beam, and a larger portion of nonvolatile tetrapyrrole is carried into the ion beam as compared to the conventional method.

\section{RESULTS AND DISCUSSION}

UV-visible absorption spectral data are presented in Table 1 . Of the 34 cores examined, 14 contained a nondetectable level of pigment. These nonproductive core samples ranged from Pleistocene to Eocene in age. In general, pigments were more abundant in the Miocene to Eocene sediments than in Pleistocene sediments (Table 1).

\section{Site 338}

Cores 11 and 17 from Site 338 contained pigments with chlorin-type spectra. In addition, another pigment fraction having the UV-visible spectrum shown in Figure 2 was isolated. A fraction of this pigment from Core 17, eluted with THF from Grade III Alumina, had a mass spectrum bearing some resemblance to those of chlorins reported by Baker (1970) and Baker and Smith $(1973,1975 a)$. At this time, we will only report the $\mathrm{m} / \mathrm{e}$ values, as a structure has yet to be assigned (see "chlorin 635," Table 2).

\section{Site 341}

Small amounts of pigment having a chlorin-like visible spectrum were found in the upper 15 to 30 meters of Pleistocene sediment (Cores 2 and 4, respectively), with increasing amounts at 64 to 67 meters (Cores 6 and 8, respectively). A marked decrease in chlorin was noted at 70 meters (Core 10). Vanadyl porphyrin was present in these Pleistocene sediments (Core 4 at $35 \mathrm{~m}$ ). (Vanadyl porphyrin was again observed in Core 344-5, Pliocene-Pleistocene, at about $30 \mathrm{~m}$ depth.) The combination of free-base chlorin and vanadyl porphyrin is unusual and unexpected. Only one occurrence of vanadyl porphyrin in DSDP sediments has been reported previously (Baker, 1971). It is generally believed that vanadyl porphyrins are thermodynamically more stable and therefore that they represent a later stage in diagensis of the chlorophyll molecule than freebase chlorins. Probably these deposits, collected from the Lofoten Basin, were derived from a mixture of very old and very young sediments. A typical UV-visible spectrum was obtained for the vanadyl porphyrin in Core 341-4 (Figure 3); in addition, there was a small peak at $590 \mathrm{~nm}$; this may be due to small amounts of rhodo-type porphyrins (Baker, 1971). Only a truncated series, with the largest $\mathrm{m} / \mathrm{e}$ peak at 541 , was obtained mass spectrometrically (Table 2). A complete series would be: $583,569,555,541,527,513$, and 499 , each 14 $\mathrm{m} / \mathrm{e}$ units apart (Baker, 1971). The $\mathrm{m} / \mathrm{e}$ peak appearing at 577 does not fit the normal expected series, however, it is indicative of the rhodo series: $456+65+14 n$ (Baker et al., 1967).

Miocene sediments (384 to $451 \mathrm{~m}$ ) collected at Site 341 contained pigments with chlorin-type spectra, nickel porphyrin chelates, and pigments having spectra similar to pigments from Site 338 ("chlorin 635"). Freebase porphyrin was also indicated by UV-visible spectra. Free-base porphyrin (DPEP) has only been noted at 2 sites (Baker and Smith, 1975a) out of more than 40 DSDP sites examined. These core samples (Cores 341$28,30,32,34$ ) were combined in order to have workable amounts of pigments (Table 1). The nickel porphyrin fraction isolated from Alumina Grade III with 1\% 1, 2 dichloroethane in benzene displayed a $1: 1 \alpha: \beta$ ratio (Figure 4). Such a ratio is markedly different than the usual 3:1 ratio. Although mass spectral analyses were attempted on this fraction, no interpretable spectra were obtained. 
TABLE 1

Tetrapyrrole Pigments in Core Samples From Leg 38

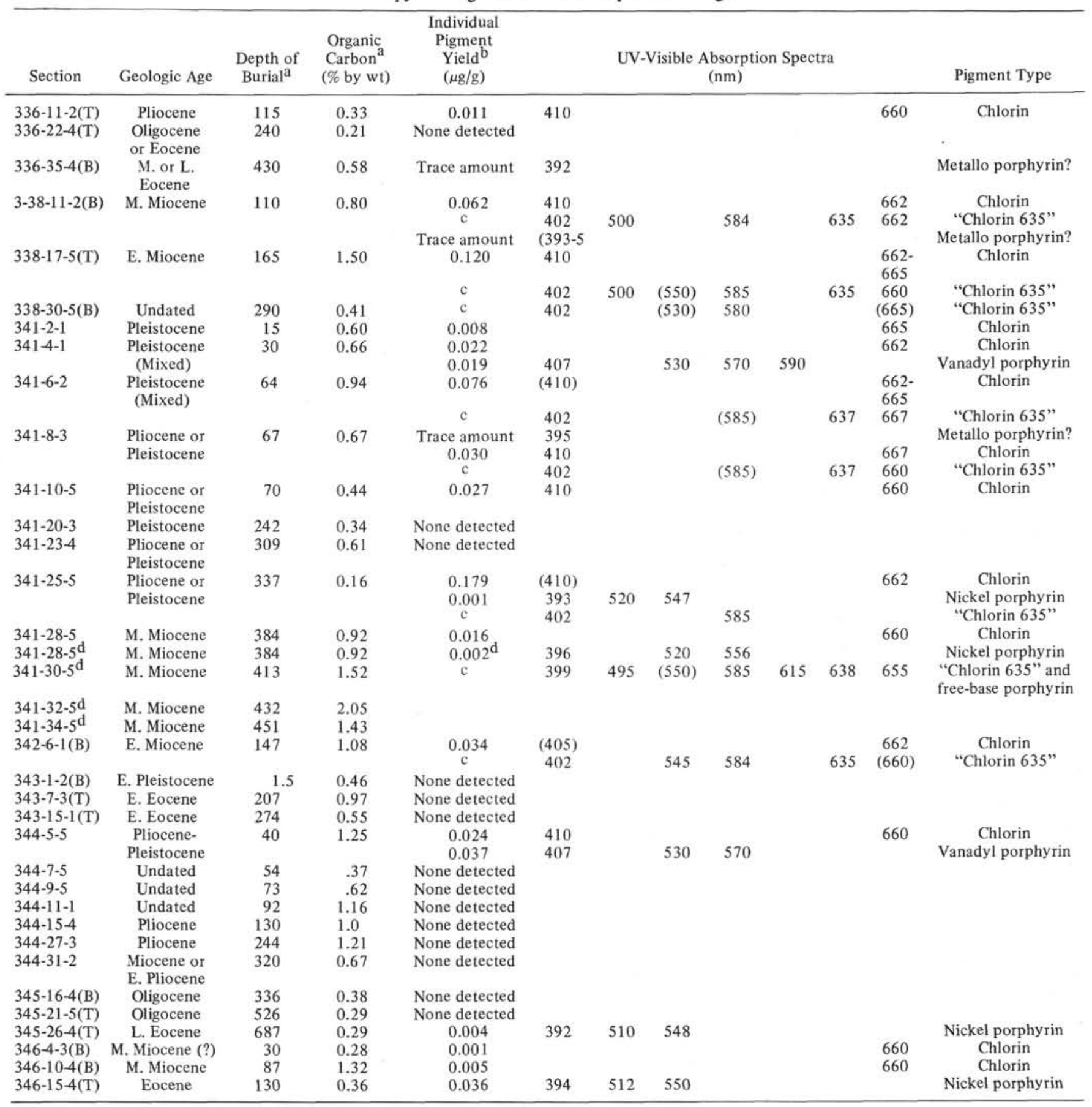

a Data obtained from Leg 38 summary.

${ }^{b}$ Pigment yield calculated by using the following molar extinction coefficients: pheophytin "a" $=64000$ at 660 nm; nickel porphyrin $=34820$ at $550 \mathrm{~nm}$; vanadyl porphyrin $=26140$ at $570 \mathrm{~nm}$.

c Not calculated.

$\mathrm{d}_{341-28,-30,-32 \text {, and }-34 \text { combined. }}$

\section{Site 342}

Chlorin-type spectra were obtained for Core 6 (early Miocene) as well as pigments with $402,584,635,660$ $\mathrm{nm}$ spectra. This is not an uncommon occurrence, since chlorins were found in Oligocene to late Eocene sediments collected during earlier legs (Baker and Smith, 1975b). The amount of chlorin found in 342-61(B) $(0.034 \mu \mathrm{g} / \mathrm{g})$ is similar to the amount of chlorin $(0.024$ to $0.09 \mu \mathrm{g} / \mathrm{g})$ reported for Miocene 


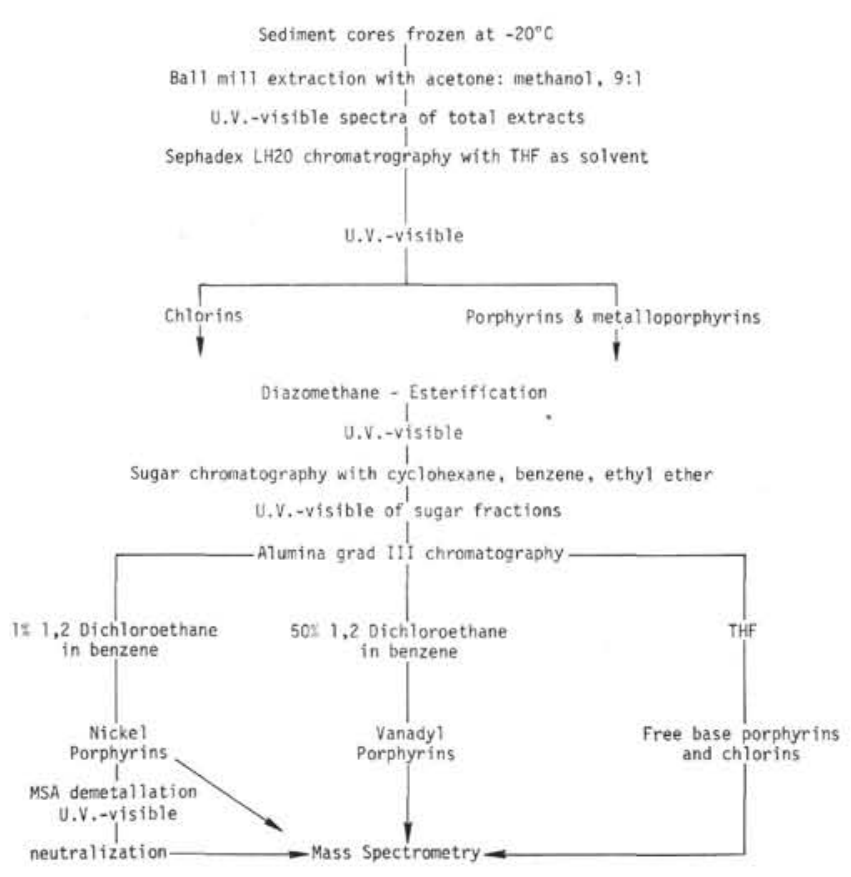

Figure 1. Experimental flow sheet.

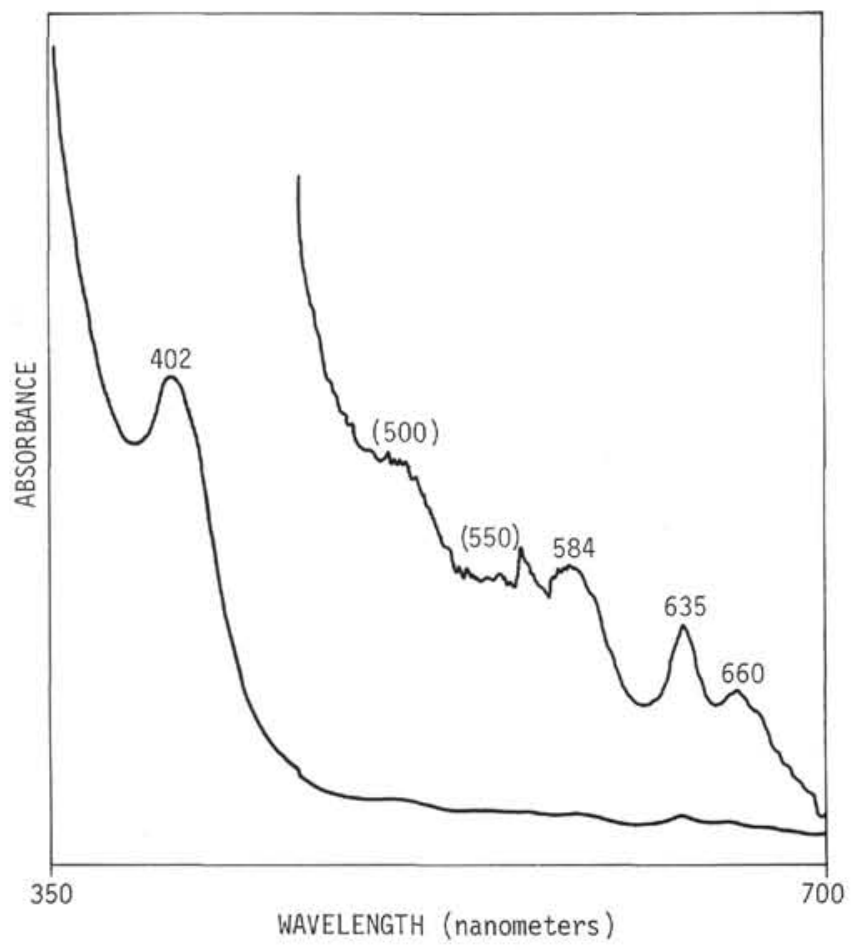

Figure 2. UV-visible spectrum of "chlorin 635" from 33817.

samples from Leg 31 sediments (Baker and Smith, 1975a).

\section{Site 346}

Small amounts of chlorin were found at 30 and 87 meters (Cores 4 and 10, respectively). Core 4 was examined to a greater extent for comparison with Cores $341-4$ and $344-5$, also from approximately 30 meters depth. The absence of vanadyl porphyrin in Core 346-4 may reflect a difference in geological setting: Site 346 was on the east slope of Jan Mayen Ridge, whereas Sites 341 and 344 were in the Lofoten Basin.

Core 15 (at $130 \mathrm{~m}$ ) contained relatively large amounts of nickel porphyrin $(0.036 \mu \mathrm{g} / \mathrm{g})$. The nickel chelate was converted to the free base by treatment with MSA at $100^{\circ} \mathrm{C}$ for 1 hour, and the free-base porphyrin with the following UV-visible spectrum was obtained after neutralization with sodium carbonate and extraction with ethyl ether: $395,495,520,563,618 \mathrm{~nm}$. Based on the nature of this absorption spectrum and mass spectral data (Table 2), this pigment was interpreted to be a mixture of DPEP and etioporphyrin (Baker, 1969). The mass spectrum displays these two series: etio $=422$ $+14 n$ and DPEP $=420+14 n$ (Baker, 1969), both series incorporating the natural abundance of $\mathrm{Ni}^{58}$ $(67.8 \%)$ and $\mathrm{Ni}^{60}(26.2 \%)$. Thus, the $\mathrm{m} / \mathrm{e}$ peaks appear in groups of three, for example, m/e 532, 534, 536. A precise interpretation of the mass spectrum would require lower background than was achieved with the small amount of sample available for this study. We estimate the DPEP: etio ratio to be $2: 1$ based on relative mass spectral peak intensities and the free-base absorption spectrum.

\section{SUMMARY}

Tetraypyrrole pigments were found in sediments ranging from Pleistocene to Eocene in age. Although chlorins were abundant in Miocene sediments, their presence was generally characteristic of younger (Pleistocene) sediments. No mass spectral analyses were made on chlorins isolated during this study. Nickel porphyrins were found in the older (Pliocene-Eocene) sediments collected during Leg 38 . The distribution of these pigments is not unlike those reported in previous DSDP studies (Smith and Baker, 1974; Baker and Smith, 1975a, b). Nickel DPEP and nickel etioporphyrin were present in at least one Eocene sediment (Core 346-15). We cannot make any statements concerning the nature of the other nickel chelates; higher concentrations would be needed in order to study their structures in greater detail.

In two Pleistocene samples vanadyl porphyrins and chlorins were found together. In Core 341-4, they were present in approximately qual concentrations, while in Core 344-5 the chlorins were one-third as abundant as the vanadyl porphyrin. Previously, vanadyl porphyrins were noted in Tertiary sediments (Baker, 1971); we suggest that the combination of chlorins and vanadyl porphyrins found here is not a normal distribution and may be due to mixing of older with younger sediments.

The presence of free-base porphyrins was indicated (by UV-visible spectra) in middle Miocene sediments of Site 341. Their occurrence was coupled with chlorin (Core 341-28), nickel porphyrin and "chlorin 635" (Cores 341-28, 30, 32, and 34). The occurrence of freebase porphyrin was noted earlier by Baker and Smith (1975a) in two Pliocene-Miocene sites. No judgment can be made concerning this rather odd mixture of tetrapyrrole pigments present in these middle Miocene sediments without a more complete study. "Chlorin 
TABLE 2

Mass Spectra of Leg 38 Tetrapyrrole Pigments

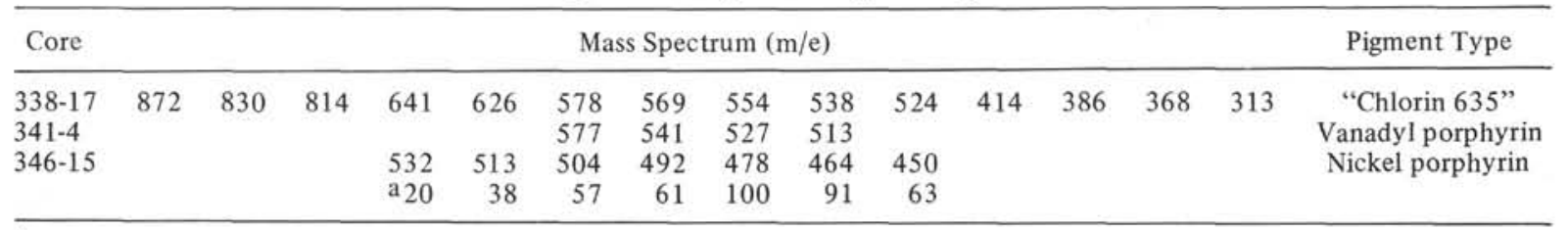

${ }^{\mathrm{a}}$ Peak intensities (normalized to 100 for the largest $\mathrm{m} / \mathrm{e}$ peak).

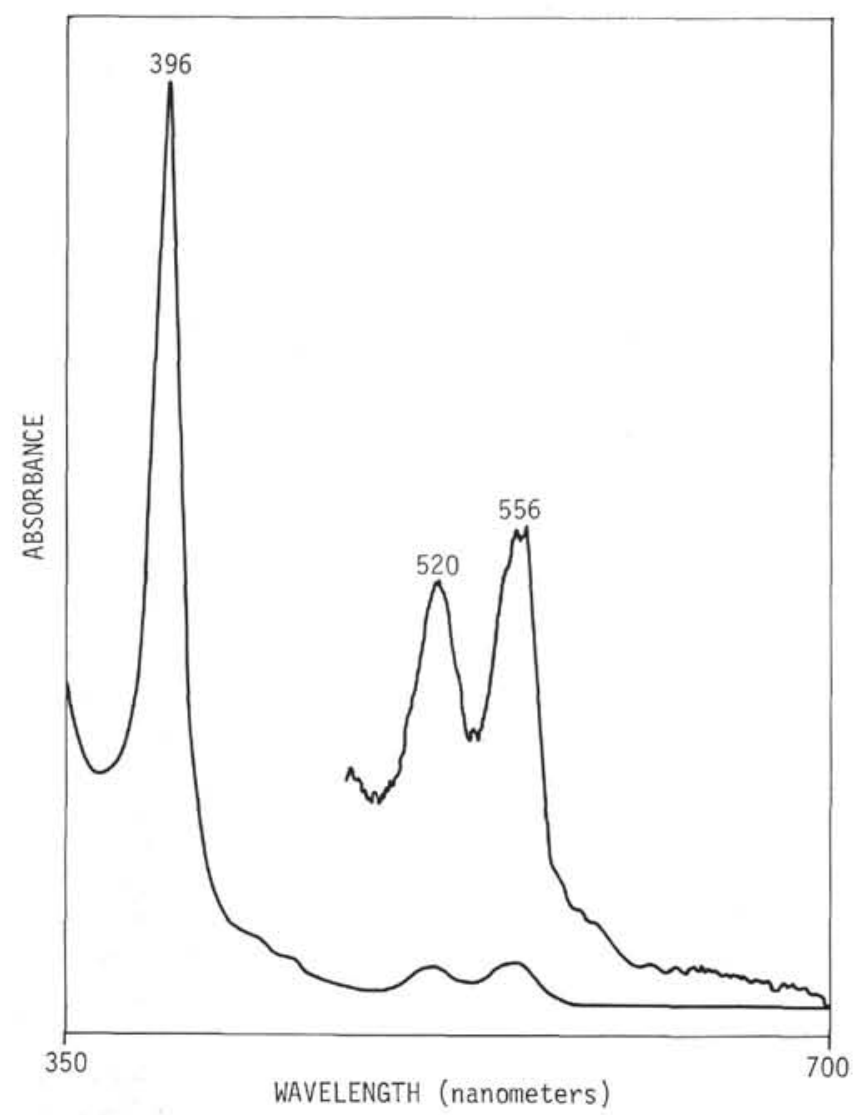

Figure 3. $U V$-visible spectrum of nickel porphyrin from core $341(28-32)$.

635," present in three Pleistocene or Pliocene and five Miocene-Eocene sediments, has not been reported in earlier DSDP sediments.

\section{ACKNOWLEDGMENTS}

This research was supported by the Oceanography Section of the National Science Foundation, Grants GA-43359X and DES 74-12438 A01.

\section{REFERENCES}

Baker, E.W., 1969. Porphyrins. In Eglington, G. and Murphy, M.T.J. (Ed.s), Organic geochemistry: New York (Spinger-Verlag), p. 479.

1970. Tetrapyrrole pigments. In Bader, R.G., Gerard, R.D., et al., Initial Reports of the Deep Sea Drilling Project, Volume 4: Washington (U.S. Government Printing Office), p. 431.

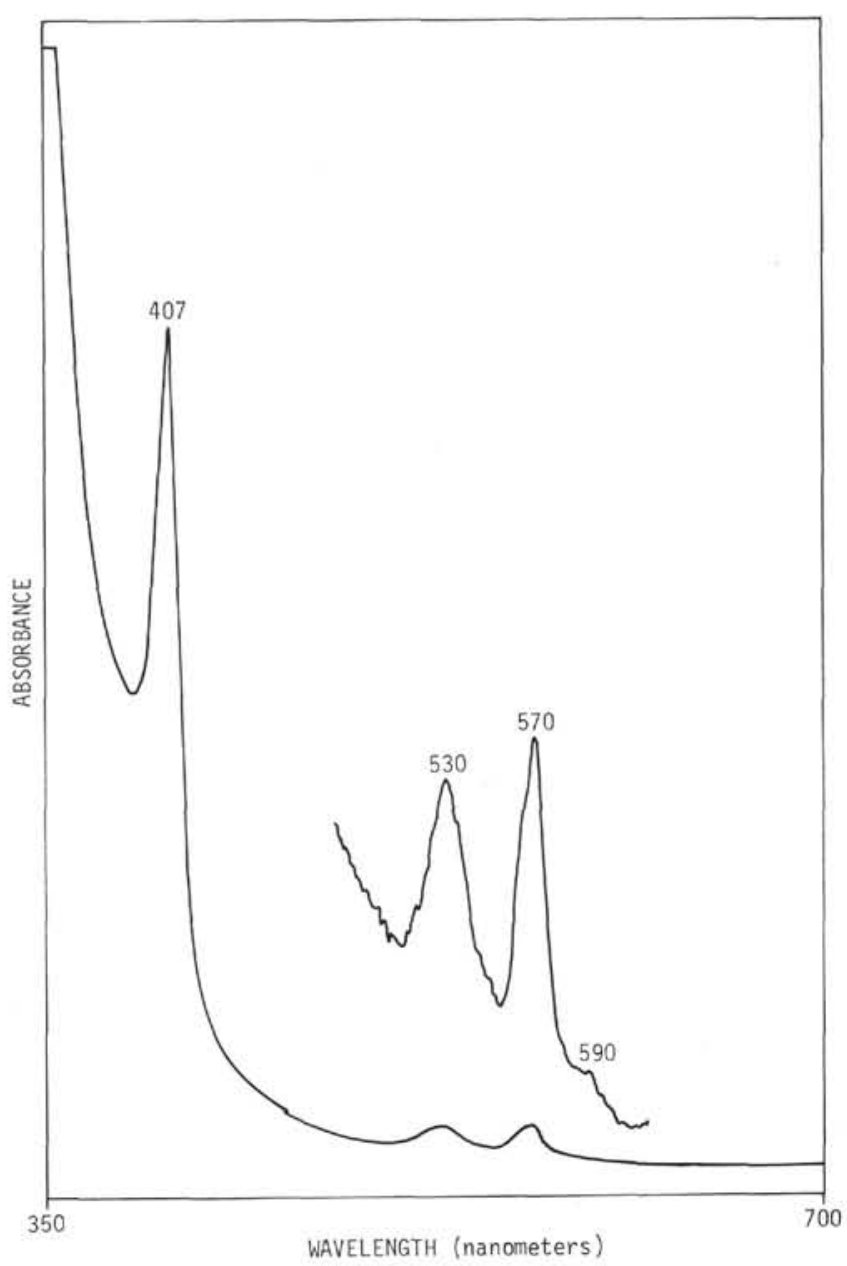

Figure 4. UV-visible spectrum of vanadyl porphyrin isolated from core 341-4.

1971. Porphyrins in deep ocean sources. Petroporphyrins from Challenger Knoll oil bearing cores: Chem. Geol., v. 7, p. 45.

Baker, E.W. and Smith, G.D., 1973. Chlorophyll derivatives in sediments, Site 147. In Heezen, B.C., MacGregor, I., et al., Initial Reports of the Deep Sea Drilling Project, Volume 20: Washington (U.S. Government Printing Office), p. 943.

1975a. Chlorophyll derivatives in DSDP Leg 31 Sediments. In Ingle, J.C., Karig, D.E., et al., Initial Reports of the Deep Sea Drilling Project, Volume 31: Washington (U.S. Government Printing Office), p. 629. 1975b. Chlorophyll derivatives in DSDP Leg 14, $20,26,27$, and 29 Sediments. In Ingle, J.C., Karig, D.E., et al., Initial Reports of the Deep Sea Drilling Project, 
Volume 31: Washington (U.S. Government Printing Office), p. 905.

Baker, E.W., Yen, T.F., Dickie, J.P., Rhodes, R.E., and Clark, L.F., 1967. Mass spectrometry of Porphyrins II: Characterization of petroporphyrins: J. Am. Chem. Soc., v. 89, p. 3631 .
Smith, G.D. and Baker, E.W., 1974. Chlorophyll derivatives in DSDP Leg 22 sediments. In von der Borch, C.C., Sclater, J.G., et al., Initial Reports of the Deep Sea Drilling Project, Volume 22: Washington (U.S. Government Printing Office), p. 677. 